\title{
Bazalt Lifi ile Güçlendirilmiş Killi Zeminin Mühendislik Özellikleri Üzerine Deneysel Araştırma
}

\author{
Ahmetcan Sungur $^{1 *}$, Mehmet Fatih Yazıc1 ${ }^{2}$, Siddıka Nilay Keskin ${ }^{3}$ \\ 1* Süleyman Demirel Üniversitesi, Fen Bilimleri Enstitüsü, İnşaat Mühendisliği Anabilim Dalı, 100/2000 YÖK Doktora Bursiyeri, Isparta, Türkiye, (ORCID: 0000- \\ 0001-6200-7601), ahmetcansungur@gmail.com \\ 2 Süleyman Demirel Üniversitesi, Mühendislik Fakültesi, İnşaat Mühendisliği Bölümü, Isparta, Türkiye, (ORCID: 0000-0002-3557-7817), mehmetyazici@sdu.edu.tr \\ ${ }^{3}$ Süleyman Demirel Üniversitesi, Mühendislik Fakültesi, İnşaat Mühendisliği Bölümü, Isparta, Türkiye, (ORCID: 0000-0002-0367-943X), nilaykeskin@sdu.edu.tr
}

(1st International Conference on Applied Engineering and Natural Sciences ICAENS 2021, November 1-3, 2021)

(DOI: $10.31590 /$ ejosat.1011881)

ATIF/REFERENCE: Sungur, A., Yazıcı, M.F. \& Keskin, S.N. (2021). Bazalt Lifi ile Güçlendirilmiş Killi Zeminin Mühendislik Özellikleri Üzerine Deneysel Araştırma. European Journal of Science and Technology, (28), 895-899.

$\ddot{\mathbf{O z}}$

Son zamanlarda düşük maliyetleri, yeterli dayanımları ve kolay ulaşılabilirlikleri nedeniyle zeminlerin güçlendirilmesinde liflerin kullanılması tekniği, geleneksel zemin güçlendirme yöntemlerine bir alternatif olarak araştırmacıların dikkatini çekmeyi başarmıştır. $\mathrm{Bu}$ çalışmada, farklı uzunluk ve miktarlarda bazalt lifi ile güçlendirilmiş kil zeminin kayma mukavemetindeki değişim direkt kesme deneyi ile araştırılmıştır. Bu amaç için, zeminin kuru ağırlığının bir yüzdesi olarak; 9 mm uzunlukta lif için \%0, \%0,5, \%0,75 ve \%1,0; $15 \mathrm{~mm}$ uzunlukta lif için \%0, \%0,5\%1,0,\%1,5, \%2,0 ve $22 \mathrm{~mm}$ uzunlukta lif için \%0, \%0,5, \%1,0 ve \%1,5 miktarlarında bazalt lif kullanılmıştır. Deneylerin sonucunda, $15 \mathrm{~mm}$ uzunluktaki bazalt liflerden zemin içerisine \%1,5 miktarında ilave edilmesi ile en yüksek kayma mukavemeti ve kohezyon değerleri elde edilmiştir. En yüksek içsel sürtünme açısı değeri ise 22 mm uzunlukta \%0,5 oranında lif ile güçlendirilmiş zeminde gözlenmiştir. Elde edilen sonuçlar çalışmanın amacına uygun olarak değerlendirilmiştir.

Anahtar Kelimeler: Bazalt lif, Zeminlerin güçlendirilmesi, Lif uzunluğu, Direkt kesme deneyi, Kayma mukavemeti.

\section{Experimental Research on the Engineering Properties of Basalt Fiber Reinforced Clayey Soil}

\begin{abstract}
In recent times, the method of using reinforcement with randomly distributed fibers of soils has attracted the attention of researchers, as an alternative method instead of traditional soil reinforcement methods, with the advantages of low cost, sufficient strength and easy accessibility. In this study, the change in shear strength of clay soil reinforced with basalt fiber in different lengths and contents was investigated by direct shear test. For this purpose, basalt fiber was used at the contents of $0 \%, 0.5 \%, 0.75 \%$, and $1.0 \%$ for 9 mm long fiber, $0 \%, 0.5 \%, 1.0 \%, 1.5 \%$, and $2 \%$ for $15 \mathrm{~mm}$ long fiber and $0 \%, 0.5 \%, 1.0 \%$ and $1.5 \%$ for $22 \mathrm{~mm}$ long fiber as a percentage of the dry weight of the soil. As a result, the highest shear strength and cohesion values were obtained by adding $15 \mathrm{~mm}$ length basalt fiber at the content of $1.5 \%$ into clay soil. The highest internal friction angle value was observed in reinforced soil with $22 \mathrm{~mm}$ long fiber at the content of \%0.5. The results were evaluated in accordance with the purpose of the study.
\end{abstract}

Keywords: Basalt fiber, Soil reinforcement, Fiber length, Direct shear test, Shear strength.

*Corresponding Author: ahmetcansungur@gmail.com 


\section{Giriş}

Düşük taşıma gücüne sahip ve/veya yüksek sıkışabilirliğe sahip zeminlerin güçlendirilmesi, şev problemleri ve stabilizasyonu, sıvılaşma potansiyelinin azaltılması gibi geoteknik uygulamalarında, zeminlerin güçlendirilmesi tekniğine sıklıkla başvurulmaktadır. Geçmişten günümüze zeminlerin güçlendirilmesi tekniği ile ilgili farklı yöntemler üzerine literatürde birçok araştırma yapılmıştır. Düşük maliyetleri, yeterli dayanımları ve kolay ulaşılabilirlikleri nedeniyle zeminlerin güçlendirilmesi amacıyla, liflerin kullanılması tekniği son zamanlarda sıkça kullanılmaktadır. Doğal lif çeşitlerinden biri olan bazalt lifi; yüksek stabilite, çekme dayanımı ve ergime sıcaklığına sahip, çevre dostu bir malzeme olarak karşımıza çıkmaktadır (Kale vd. 2020). İnşaat mühendisliği uygulamalarında genellikle beton içerisinde güçlendirme malzemesi olarak kullanılmakta olan bazalt liflerin, zeminlerin güçlendirilmesinde kullanımı üzerine literatürde yapılan çalışmaların kısıtlı kaldığı görülmektedir. Literatürde rastgele dağıtılmış bazalt lifler ile zeminlerin güçlendirilmesi üzerine yapılan çalışmalardan bazıları aşağıda verilmiştir.

Gao vd. (2015), optimum su muhtevası ve maksimum kuru birim hacim ağırlık koşulları altında hazırladıkları bazalt lif takviyeli kil zeminin serbest basınç mukavemeti üzerine, lif uzunluğu ve miktarının etkilerini araştırmışlardır. Sonuç olarak en yüksek dayanım artışını optimum lif içeriğinin \%0,25, lif uzunluğunun ise $12 \mathrm{~mm}$ olduğunda elde etmişlerdir. Küçükosmanoğlu (2019), kil zeminin şişme davranışı ve Kaliforniya taşıma oranı değeri üzerine farklı uzunluk ve miktarlardaki bazalt lif ilavesinin etkilerini araştırmıştır. Sonuç olarak \%0,2 miktarında $6 \mathrm{~mm}$ uzunlukta lif ilavesi ile katkısız zemine nispeten şişme miktarının 6,73 kat azaldığını ve Kaliforniya taşıma oranı değerinin de 3,3 kat iyileştiğini gözlemlemiştir. Ocakbaşı (2019), bazalt lifi ile güçlendirilmiş kil zeminin serbest basınç mukavemeti üzerine lif miktarı ve uzunluğunun etkilerini araştırmıştır. Sonuç olarak en yüksek serbest basınç mukavemetinin $24 \mathrm{~mm}$ uzunlukta \%2 lif içeriğine sahip kompozit numunede meydana geldiğini belirtmiştir. Ndepete ve Sert (2016), düşük plastisiteli siltli bir zeminin kayma dayanımı üzerine bazalt liflerin etkilerini incelemişlerdir. Bazalt lif içeriğinin artması ile siltli zeminin dayanımının arttı̆̆ını, dayanımdaki maksimum iyileşmeyi temsil eden optimum lif içeriğinin ise \%1,5 olduğunu ifade etmişlerdir. Ayrıca $24 \mathrm{~mm}$ uzunluğunda lif ile güçlendirilmiş siltli zeminin daha yüksek dayanıma sahip olduğunu gözlemlemişlerdir. George ve Ramya (2017), farklı uzunluk ve miktarda bazalt lifi ilavesi ile kür süresinin yüksek plastisiteli organik yerel bir zeminin geoteknik özelliklerinin iyileştirilmesi üzerine etiklerini araştırmışlardır. Maksimum dayanım artışını, $10 \mathrm{~mm}$ uzunluğunda, \%0,05 lif içeriğinde ve 28 günlük kür süresi sonunda elde etmişlerdir.

$\mathrm{Bu}$ çalışmada; düşük plastisiteli bir kil zeminin kayma mukavemeti özellikleri üzerine farklı miktarlarda ve farklı uzunluklardaki bazalt lifinin etkileri araştırılmıştır. Bu amaç için $9 \mathrm{~mm}$ uzunluktaki bazalt liflerden ağırlıç̧a \%0,5, \%0,75, \%1,0; $15 \mathrm{~mm}$ uzunluktaki liflerden $\% 0,5, \% 1,0, \% 1,5, \% 2,0$ ve $22 \mathrm{~mm}$ uzunluktaki liflerden ise $\% 0,5, \% 1,0, \% 1,5$ oranlarında kullanılmıştır. Güçlendirilmiş ve güçlendirilmemiş kil zeminin kayma mukavemeti direkt kesme deneyi ile incelenmiştir.

\section{Materyal ve Yöntem}

\subsection{Malzemeler}

$\mathrm{Bu}$ çalışmada kullanılan ince daneli zemin numunesinin üzerinde sınıflandırma ve standart proktor deneyleri yapılmıştır. Deney sonuçları Tablo 1'de verilmiştir. Deneylerden elde edilen veriler sonucunda zemin sınıfı, Birleştirilmiş Zemin Sınıflandırma Sistemi'ne göre düşük plastisiteli kil (CL) olarak belirlenmiştir.

Tablo 1. İnce daneli zeminin özellikleri

\begin{tabular}{|c|c|}
\hline Özellikler & Değer \\
\hline Likit limit (\%) & 35 \\
\hline Plastik limit (\%) & 19 \\
\hline Plastisite indisi (\%) & 16 \\
\hline Max. kuru yoğunluk (gr/cm $\left.{ }^{3}\right)$ & 1,75 \\
\hline Optimum su muhtevası (\%) & 15 \\
\hline Özgül gravite & 2,73 \\
\hline No \#200 Elek Alt1 Malzeme (\%) & 98,8 \\
\hline
\end{tabular}

Kil zeminin stabilizasyonu için çapları 9-23 $\mu \mathrm{m}$ arasında değişen ve 9,15 ve $22 \mathrm{~mm}$ uzunluklara sahip bazalt lifler kullanılmıştır (Şekil 1). Bazalt liflerinin üretici firmadan temin edilen fiziksel ve mekanik özellikleri Tablo 2'de verilmiştir.

\subsection{Numunelerin Hazırlanması}

Rastgele dağıtılmış ayrık lifler ile zeminlerin güçlendirilmesi yönteminde, lif-zemin karışımlarının hazırlanmasında liflerin zemin içerisinde homojen ve izotropik dağılmasını sağlamak ve liflerin topaklanmasını önlemek için literatürde birçok yöntem kullanılmaktadır. Genellikle etüvde kurutulan zemine lif malzemesi karıştırılmakta, daha sonra bu karışıma belirlenen miktarda su ilave edilmektedir (Gao vd. 2015, Soğanc1 2015, Motiram vd. 2018, Tran vd. 2018, Liu vd. 2020). Bu çalışmada lif-zemin karışımlarının hazırlanmasında yukarıdaki yöntem benimsenmiştir. Ayrıca homojen bir lif-zemin karışımının elde edilebilmesi için önemli parametrelerden birisi olan karıştırma yöntemi olarak literatürde mekanik karıştırıcı, mikser, el ile karıştırma yöntemi, tamburlu karıştırıcı gibi yöntemler kullanılmaktadır. Laboratuvar ortamında lif-zemin karışımlarının hazırlanması aşamasında liflerin dağılımının gözlenebilmesine olanak tanıdığı için el ile karıştırma yöntemi çokça tercih edilmektedir (Bouhicha vd. 2005, Najjar vd. 2014, Ateş 2016, Soltani vd. 2018, Taha vd. 2020). Bu çalışmada, etüvde kurutulan kil zemin numunesinden standart proktor deneyinden elde edilen maksimum kuru birim hacim ağırlık değerine karşılık gelecek miktarda alınmıştır. Daha sonra ilgili uzunluk ve miktardaki bazalt lifler rastgele bir şekilde ve yavaş yavaş kuru kil zemine ilave edilerek karıştırılmıştır. Kuru kil-lif karışımına optimum su muhtevası değerinde su ilave edilmiş ve liflerin zemin içerisinde eşit bir şekilde dağılımı sağlanana kadar lif-kil-su karışımı karıştırılmıştır. Güçlendirme elemanı olarak $9 \mathrm{~mm}$ uzunluktaki bazalt liflerden ağırlıkça \%0,5, \%0,75, \%1,0; $15 \mathrm{~mm}$ uzunluktaki liflerden ağırlıkça \%0,5, \%1,0, \%1,5, \%2,0 ve 22 mm uzunluktaki liflerden ise ağırlıça \%0,5, \%1,0, \%1,5 miktarlarında kullanılmıştır. Bu karışımlardan hazırlanan her bir numune $60 \mathrm{~mm}$ x $60 \mathrm{~mm}$ x $20 \mathrm{~mm}$ boyutlara sahip kesme kutusu halkası içerisinde optimum su muhtevası ve maksimum kuru birim hacim ağırlıkta sıkıştırılmış ve direkt kesme deneyine tabi tutulmuştur. 
Tablo 2. Bazalt lifin özellikleri

\begin{tabular}{|c|c|c|c|c|c|}
\hline Lif türü & $\begin{array}{c}\text { Özgül Ağırlık } \\
\left(\mathrm{gr} / \mathrm{cm}^{3}\right)\end{array}$ & $\begin{array}{c}\text { Çekme Mukavemeti } \\
(\mathrm{GPa})\end{array}$ & $\begin{array}{c}\text { Elastisite Modülü } \\
(\mathrm{GPa})\end{array}$ & $\begin{array}{c}\text { Lif Çap1 } \\
(\mu \mathrm{m})\end{array}$ & $\begin{array}{c}\text { Lif Uzunluğu } \\
(\mathrm{mm})\end{array}$ \\
\hline Bazalt & $2,60-2,80$ & 4,84 & 89 & $9-23$ & $9,15 \mathrm{ve} 22$ \\
\hline
\end{tabular}

\subsection{Deney Prosedürü}

Direkt kesme deneyinde kırılmak üzere $60 \mathrm{~mm}$ x $60 \mathrm{~mm}$ x 20 $\mathrm{mm}$ boyutlara sahip olacak şekilde hazırlanan numuneler, 60, 120 ve $240 \mathrm{kPa}$ büyüklüğündeki normal gerilme değerlerinde, 1 $\mathrm{mm} / \mathrm{dk}$ yatay deplasman hızında kesilmiştir. Her bir numune \%15 birim boy değişimine sahip olana kadar yüklenmiştir. $\mathrm{Bu}$ çalışmada kullanılan direkt kesme cihazı ve bu cihazda kesilen numunelere ait görseller Şekil 2 'de verilmiştir.

\section{Bulgular ve Tartışma}

Farklı uzunluklarda bazalt lif ile güçlendirilmiş ve lif katkısız düşük plastisiteli kil zeminin pik kayma mukavemeti, içsel sürtünme açısı ve kohezyon değerleri direkt kesme deneyi yardımıyla incelenmiştir. Deneyler sonucunda elde edilen grafikler Şekil 3 ve Şekil 4'te sunulmuştur. Şekil 3'e bakıldığında, $15 \mathrm{~mm}$ uzunluğa sahip lif kullanılması durumunda en yüksek kayma mukavemeti artışlarının meydana geldiği görülmektedir. 15 mm'den daha uzun lif kullanılması durumunda homojen lif-kil karışımlarının hazırlanması daha zor hale gelmekte ve liflerin topaklanma olasılığg artmaktadır (Cui vd. 2018). Bu durumun, lif uzunluğunun 15 mm'den daha büyük olması durumunda kayma mukavemetinde meydana gelen azalışın nedeni olduğu düşünülmektedir. Ayrıca tüm lif uzunlukları için $240 \mathrm{kPa}$ büyüklüğünde normal gerilme altında daha düşük normal gerilmelere nispeten kayma mukavemetinde daha önemli miktarda artışlar meydana gelmektedir. Tüm lif uzunlukları için genel olarak lif miktarının artması ile güçlendirilmiş zeminin kayma mukavemeti, lif takviyesiz zemine nispeten artmaktadır. Bazalt lif ile güçlendirilmiş kil zeminde en yüksek kayma mukavemeti değerinin, $9 \mathrm{~mm}, 15 \mathrm{~mm}$ ve $22 \mathrm{~mm}$ uzunlukta lifler için sırasıyla ağırlıç̧a \%0,75, \%1,5 ve \%1,0 oranlarında lif ilave edilmesiyle elde edildiği görülmektedir (Şekil 3). Bazalt lif ile güçlendirilmiş düşük plastisiteli kil zemin içerisine $9 \mathrm{~mm}$ uzunlukta \%0,75 miktarında lif ilave edilmesi ile kayma mukavemetinde meydana gelen en yüksek artışın \%12,66 olduğu, $15 \mathrm{~mm}$ uzunlukta \%1,5 oranında lif ilave edilmesi ile bu artışın $\% 21,91$ değerine ulaştığ $1,22 \mathrm{~mm}$ uzunlukta \%1 içeriğinde lif ilave edilmesi ile ise bu artışın \%17,36'ya düştüğü sonucu elde edilmiştir. $9 \mathrm{~mm}$ uzunlukta lif ile güçlendirilmiş kil zeminde, lif içeriğinin artması ile güçlendirilmemiş zemine kıyasla kohezyon değerinde küçük azalışlar meydana gelmektedir (Şekil 4a). Buna karşılık lif içeriğinin \%0,75'e kadar artması ile içsel sürtünme açısı artmakta, bu değerden daha büyük lif içeriklerinde ise azalmaktadır (Şekil 4b). Tekrardan Şekil 4'e bakıldığında, 15 mm uzunlukta lif kullanılması durumunda lif miktarının \%1,5'e kadar artması ile hem kohezyon hem de içsel sürtünme açısı değerinin arttığ 1 , bu değerden daha büyük lif içeriklerinde ise azaldığ görülmektedir. Öte taraftan $22 \mathrm{~mm}$ uzunlukta lif ile güçlendirilmiş kil zeminde, \%0,5 miktarında lif kullanılması durumunda kohezyon değerinin lif katkısız zemininkine oranla azaldığı, içsel sürtünme açısının ise arttığı gözlenmektedir. \%0,5’ten sonra lif miktarının artması ile ise kohezyon değeri artmakta, içsel sürtünme açısı ise azalmaktadır. En yüksek içsel sürtünme açısı değeri 22 mm uzunlukta \%0,5 miktarında lif ile güçlendirilmiş kil zeminde, en yüksek kohezyon değeri ise kil zemin içerisinde 15 mm uzunluğa sahip liflerden $\% 1,5$ oranında kullanılması durumunda elde edilmiştir.

\section{Sonuçlar}

$\mathrm{Bu}$ çalışmada düşük plastisiteli kil zeminin kayma mukavemetine farklı uzunluk ve miktarlarda bazalt lifi ilavesinin etkileri direkt kesme deneyi cihazı ile araştırılmıştır. Sonuç olarak hem lif uzunluğunun hem de lif miktarının kayma mukavemeti özellikleri üzerinde önemli bir etkiye sahip olduğu gözlenmiştir. Deneylerden elde edilen sonuçlar aşağıda verilmiştir.

Zemin içerisinde $22 \mathrm{~mm}$ uzunlukta \%0,5 içeriğinde lif kullanılması durumunda en büyük içsel sürtünme açısı değeri elde edilmiştir.

En yüksek kohezyon değeri, $15 \mathrm{~mm}$ uzunlukta \%1,5 miktarında bazalt lif ile güçlendirilmiş kil zeminde gözlenmiştir.

Kayma mukavemeti bakımından en yüksek artışların $9 \mathrm{~mm}$ uzunluğa sahip lif için \%0,75; 15 mm uzunluğunda lif için \%1,5; $22 \mathrm{~mm}$ uzunluğunda lif için ise $\% 1,0$ oranlarında meydana geldiği belirlenmiştir. $15 \mathrm{~mm}$ uzunlukta bazalt liflerinden \%1,5 miktarında kullanılması durumunda en yüksek kayma mukavemeti değerine ulaşılmıştır.

15 mm uzunluğa kadar lif uzunluğunun artması ile kayma mukavemetinin arttığı, bu değerden daha büyük lif uzunluklarının

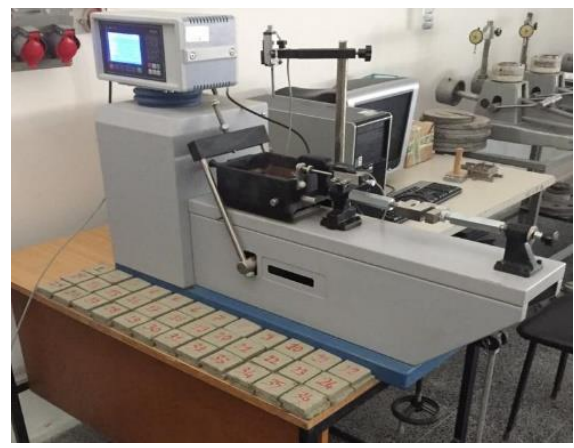

Şekil 2. Direkt kesme cihazı vekesilen numuneler 

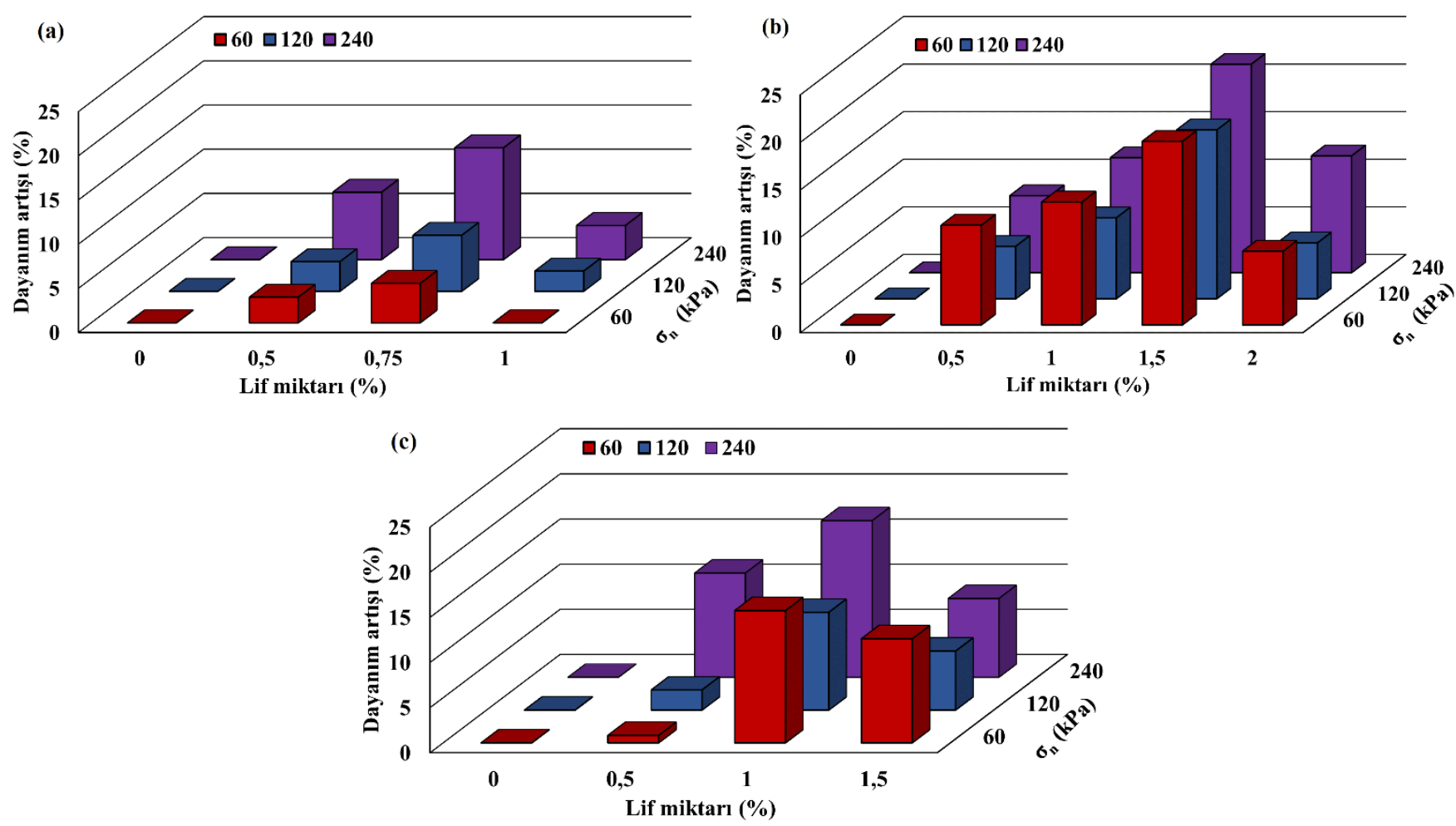

Şekil 3. (a) $9 \mathrm{~mm}$, (b) $15 \mathrm{~mm}$, (c) $22 \mathrm{~mm}$ uzunlukta bazalt lifi ile güçlendirilmiş kil zeminin kayma mukavemeti artışına normal gerilme $\left(\sigma_{\mathrm{n}}\right)$ ve lif miktarının etkisi
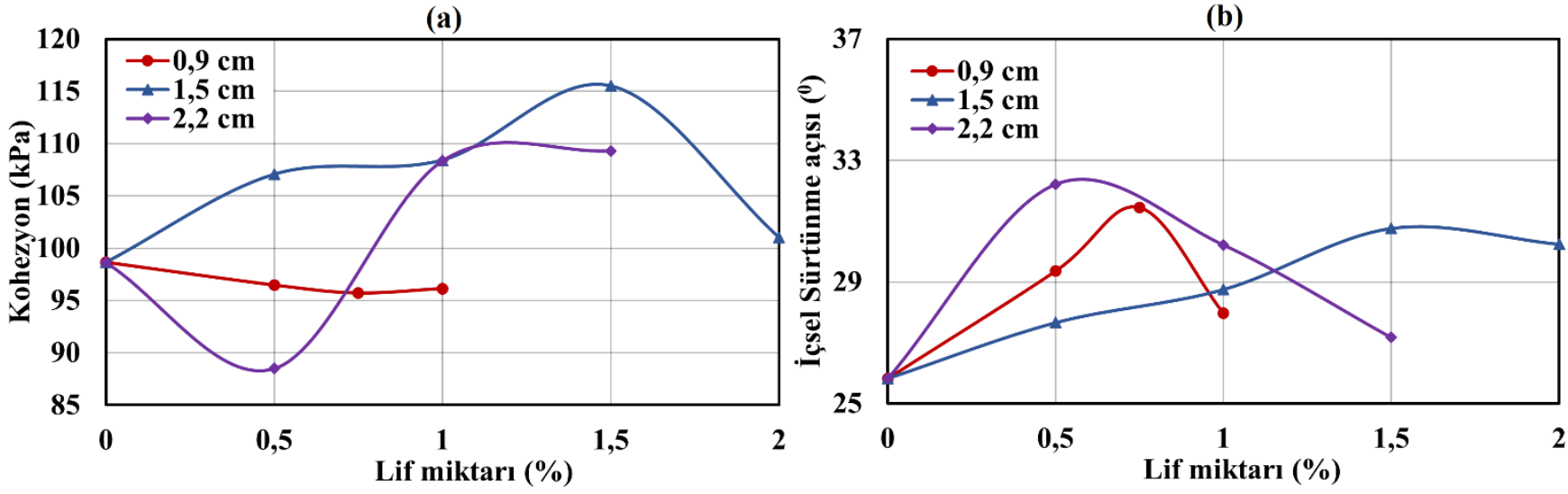

Şekil 4. Farklı uzunluklara sahip lifle güçlendirilmiş kil zeminin (a) kohezyon ve (b) içsel sürtünme açısının değişimi

kullanılması sonucunda meydana gelen lif topaklanmaları nedeniyle kayma mukavemetinin azaldığı gözlenmiştir.

Tüm numuneler için kayma mukavemetindeki en yüksek artışlar $240 \mathrm{kPa}$ büyüklüğündeki normal gerilme altında gerçekleşmiştir.

\section{Kaynaklar}

Ateş, A. (2016). Mechanical properties of sandy soils reinforced with cement and randomly distributed glass fibers (GRC). Composites Part B: Engineering, 96, 295-304.

Bouhicha, M., Aouissi, F., \& Kenai, S. (2005). Performance of composite soil reinforced with barley straw. Cement and concrete composites, 27(5), 617-621.

Cui, H., Jin, Z., Bao, X., Tang, W., \& Dong, B. (2018). Effect of carbon fiber and nanosilica on shear properties of silty soil and the mechanisms. Construction and Building Materials, 189, 286-295.

Gao, L., Hu, G., Xu, N., Fu, J., Xiang, C., \& Yang, C. (2015). Experimental study on unconfined compressive strength of basalt fiber reinforced clay soil. Advances in Materials Science and Engineering, 2015, 1-8.

George, G. P., \& Ramya, K. (2017). A Study on the Effect of Basalt Fiber in Organic Soil. IOSR Journal of Mechanical and Civil Engineering, 4, 13-17.

Kale, R. Y., Neha, D., Sakshi, M., Gaurav, A., Pranit, J., Vaishnavi, R., \& Chetan, R. (2020). Soil stabilization by using basalt fibers. International Journal of Scientific Research \& Engineering Trends, 6(3), 1931-1935.

Küçükosmanoğlu, M. (2019). Bazalt Fiberin zemin iyileştirilmesinde kullanımı (Yüksek lisans tezi, Sakarya Üniversitesi). 
Liu, C., Lv, Y., Yu, X., \& Wu, X. (2020). Effects of freeze-thaw cycles on the unconfined compressive strength of straw fiberreinforced soil. Geotextiles and Geomembranes, 48(4), 581590.

Motiram, P. V., Rohit, C., Tushar, K., Ayushi, C., Bhushan, G., \& Deepali, C. (2018). Study of basalt fiber on compaction characteristics of black cotton soil. International Journal for Research in Engineering Application Management (IJREAM), 850-853.

Najjar, S. S., Sadek, S., \& Taha, H. (2014). Use of hemp fibers in sustainable compacted clay systems. In Geo-Congress 2014: Geo-characterization and Modeling for Sustainability (pp. 1415-1424).

Ndepete, C. P., \& Sert, S. (2016). Use of basalt fibers for soil improvement. Acta Physica Polonica A, 130(1), 355-356.

Ocakbaşı, P. (2019). Bazalt fiber katklsinin killi zeminlerin drenajslz kayma direncine etkisi (Yüksek lisans tezi, Sakarya Üniversitesi).

Soğanc1, A. S. (2015). The effect of polypropylene fiber in the stabilization of expansive soils. International Journal of Geological and Environmental Engineering, 9(8), 994-997.

Soltani, A., Deng, A., \& Taheri, A. (2018). Swell-compression characteristics of a fiber-reinforced expansive soil. Geotextiles and Geomembranes, 46(2), 183-189.

Taha, M. M., Feng, C. P., \& Ahmed, S. H. (2020). Influence of polypropylene fibre (PF) reinforcement on mechanical properties of clay soil. Advances in Polymer Technology, 2020.

Tran, K. Q., Satomi, T., \& Takahashi, H. (2018). Effect of waste cornsilk fiber reinforcement on mechanical properties of soft soils. Transportation Geotechnics, 16, 76-84. 